\title{
INDDCE TEMÁTICO
}

\section{ABORTO}

* Conceituação do crime de aborto. (a. 3, n. 3, p. 304-312, dez. 1955).

ABUSO DO DIREITO

* Condenação do abuso do direito. (a. 12, n. 12, p. 49-54, 1969).

\section{AC̣ÃO CAUTELAR}

" Ações cautelares. (a. 21, n. 21, p. 29-62, 1983/84).

" Maridados e sentenças liminares. (a. 14, n. 14, p. 7-28, 1971).

\section{AÇÃO RESCISÓRIA}

* Ação rescisória e hcmologação de transação. a. 19, n. 19, p. 101-116, 1978/79/80.

AÇÃO REVOCATÓRIA

* Notas sobre a ação revocatória. (a. 13, n. 13, p. 207-220, 1970).

\section{ACIDENTE AÉREO}

* Abalroamento aéreo. (a. 3, n. 3, p. 146-171, dez. 1955). ACIDENTE DE TRABALHO

" Acidente de trabalho e previdência social. (a. 11, n. 11, p. 161-172, 1968).

\section{AÇÕES}

* Classificação das ações. (a. 18, n. 18, p. 71-82, 1976/77).

\section{ADOÇÃO}

*Adoção. (a. 1, n. 1, p. 147-156, dez. 1953).

* A adoção e sua nova lei. (a. 6/7, n. 6/7, p. 211-220, 1958/59).

\section{ADVOGADO}

" O advogado e a justiça do trabalho: em homenagem a um senhor advogado. (a. 25, n. 25, p. 125-138, 1989). 


\section{ALIENAÇÃO FIDUCIÁRIA}

* Nulidade da alienação fiduciária quando o empréstimo não se destina à aquisição do bem dado em garantia. (a. 25, n. 25 , p. $119-124,1989$ ).

ARREMATAÇÃO

* Desnecessidade da presença do Juiz ao ato de arrematação no sistema do código de processo civil. (a. 21, n. 21 , p. 101-120, 1983/84).

ATO ADMINISTRATIVO

* Ato administrativo: conceito e elementos. (a. 22, n. 22, p. 6-121, 1985).

* Meios de invalidar o ato administrativo no Brasil. (a. 23, n. 23 , p. $37-50,1986)$.

\section{CASAMENTO}

* O êrro no casamento. (a. 2, n. 2, p. 394-405, dez. 1954).

* Legitimação per subsequens matrimonium. (a. 3, n. 3, p. 277-296, dez 1955).

* Velhice e casamento. (a. 5, n. 5, p. 166-192, dez. 1957).

CÓDIGO CIVIL

* O código civil português de 1966. (a. 12, n. 12, p. 101-114. 1969).

* A posse no código civil brasileiro. (a. 10, n. 10, p. 43-50, 1964/67).

CÓDIGO CIVIL (anteprojeto)

* A parte geral do anteprojeto de código civil brasileiro. (a. 15, n. 15 , p. $137-161,1972$ ).

* Sugestões ao anteprojeto do código civil. (a. 15, n. 15, p. 74-129, 1972.

CÓDIGO CIVIL (Portugal)

* Notícia sobre a parte geral do novo código civil português. (a. 12, n. 12, p. 55-92, 1969).

CÓDIGO DE PROCESSO CIVIL (Anteprojeto)

* Algumas inovações no anteprojeto de código de processo civil. (a. 13, n. 13, p. 155-166, 1970).

CÓDIGO PENAL (Anteprojeto)

* Aspectos do anteprojeto de código penal. (a. 9, n. 9, p. 85-122, 1961/63). 
" Erro de fato e erro de direito no anteprojeto de código penal. (a. 9, n. 9, p. 33-52, 1961/63).

* Relatório sobre o anteprojeto da parte especial do código penal. (a. 22, n. 22, p. 180-185, 1985).

* Sobre o anteprojeto de novo código penal. (a. 9, n. 9, p. 57-62, 1961/63).

COISA JULGADA

* Eficácia da sentença e coisa julgada perante terceiros. (a. 25, n. 25, p. 93-108, 1989).

COMPRA E VENDA

* Transformação do direito. (a. 3, n. 3, p. 337-347, dez. 1955).

CONCUBINATO

* O concubinato e a posição jurídica da concubina. (a. 12 , n. 12, p. 271-276, 1969).

\section{CONDOMÍNIO}

* Do condomínio edilício e suas fontes. (a. 17, n. 17, p. 125-134, 1974/75).

* Liquidação de condomínio. (a. 15, n. 15, p. 162-165, 1972).

CONSTITUIÇÃO

* A constituição de 1967 e o direito civil. (a. 17, n. 17, p. $53-68,1974 / 75)$.

CONTENCIOSO ADMINISTRATIVO

* Aspectos de la sentencia del tribunal de lo contencioso administrativo. (a. 10, n. 10, p. 23-42, 1964/67).

CONTRATO COMERCIAL

* O contrato de concessão de venda com exclusividade (concessão comercial). (a. 15, n. 15, p. 208-247, 1972).

CONTRATOS (Polônia)

* Aspectos gerais do direito contratual polonês. (a. 12, n. 12 , p. 11-38, 1969).

COOPERATIVISMO

* Cooperativismo e comunidade. (a. 6/7, n. 6/7, p. 188-202, 1958/59).

CRIME

* A mulher e o crime. (a. 3, n. 3, p. 132-145, dez. 1955). 
CRIME CONTINUADO

* Aspectos do crime continuado. (a. 12. n. 12, p. 137-150, 1969).

* Revisão do crime continuado. (a. 12, n. 12, p. 173-190, 1969).

CRIME CONTRA A ECONOMIA POPULAR

* Dos crimes contra a economia popular. (a. 2, n. 2, p. 314-326, dez. 1954).

CRIME CONTRA OS COSTUMES

* Algumas anotações sobre os crimes contra os costumes. (a. 22, n. 22, p. 224-235, 1985).

CRIME POLÍTICO

* Apontamentos sobre o crime político. (a. 14, n. 14, p. 29-44, 1971).

CRIME POR OMISSÃO

* Crimes omissivos. (a. 20, n. 20, p. 71-104, 1981/82).

CRIMINALIDADE

* Repressão internacional da criminaildade. (a. 1, n. 1, p. 121-146, dez. 1953).

CRIMINOLOGIA

* A criminologia de Clóvis Bevilacqua. (a. 8, n. 8, p. 7-21, 1960).

CULPA

"Responsabilidade sem culpa. (a. 4. n. 4, p. 234-250, dez. 1956).

CULPABILIDADE

* Aspectos da culpabilidade no direito penal. (a. 10, n. 10, p. 89-106, 1964/67).

* As causas da exclusão da culpabilidade do novo código penal. (a. 15, n. 15, p. 166-184, 1972).

* A culpabilidade no novo código. (a. 13, n. 13, p. 139-144, 1970).

DANOS (Direito perial)

* Da reparação do dano causado pelo crime. (a. 13, n. 13, p. 89-104, 1970).

DELINQÜÊNCIA

* Delinqüência de menores. (a. 2, n. 2, p. 327-373, dez. 1954). 
* A recuperação social dos delinqüentes. (a. 5, n. 5, p. 68-85, dez. 1957).

\section{DELITO}

* Momentos da conduta. (a. 10, n. 10, p. 131-138, 1964/67). DENUNCIAÇÃO DA LIDE

* Denunciação da lide. (a. 21, n. 21, p. 63-74, 1983/84). DESAPROPRIAÇÃO

* Associação Comercial de São Paulo - Instituto Jurídico. (a. 14, n. 14, p. 73-106, 1971).

* A desapropriação por utilidade pública no direito brasileiro e os direitos de terceiros. (a. 19, n. 19, p. 40-62, 1978/79/80).

* Do controle judicial das desapropriações por interesse público. (a. 18, n. 18, p. 51-70, 1976/77).

* Garantias jurídicas que protegem a propriedade nas desapropriações. (a. 20, n. 20. p. 39-50, 1981/82).

\section{DESENVOLVIMENTO ECONÔMICO}

* Fatores de desenvolvimento. (a. 10, n. 10, p. 107-130, 1964/67).

* O problema da paz e o subdesenvolvimento econômico. (a. 8, n. 8, p. 44-54, 1960).

\section{DIREITO, ENSINO DO}

* Direito: ensino, pesquisa, teoria e prática. (a. 25, n. 25 , p. 109-118, 1989).

* O ensino jurídico no Brasil. (a. 1, n. 1, p. 48-63, dez. 1953).

* O estudo do direito no Brasil e no Paraná. (a. 1, n. 1, p. 157-169, dez. 1953).

* O novo currículo mínimo de direito e o direito internacional. (a. 15, n. 15, p. 7-14, 1972).

* Novos rumos à didática dos cursos jurídicos. (a. 4, n. 4, p. 285-297, dez. 1956).

* A positividade como expressão do direito. (a. 4, n. 4, p. 105-109, dez. 1956).

* O problema da definição do direito. (a. 2, n. 2, p. 136-147, dez. 1954). 
- Sistemas y experiencias en enseñanza practica o aplicados para las profesiones jurídicas. (a. 10, n. 10, p. 75-88, 1964/67).

" Sobre a problemática: certeza no direito. (a. 6/7, n. 6/7, p. 221-227, 1958/59).

\section{DIREITO A INTIMIDADE}

" Considerações sobre o direito à intimidade das pessoas jurídicas. (a. 25, n. 25, p. 81-92, 1989).

\section{DIREITO ADMINISTRATIVO}

" A atividade administrativa do Estado. (a. 17, n. 17, p. 69-124, 1974/75).

* Direito, administração, Estado. (a. 1, n. 1, p. 64-72, dez. 1953).

* O direito administrativo no Brasil. (a. 9, n. 9, p. 53-56, 1961/63).

* Processo e direito administrativo. (a. 2, n. 2, p. 122-135, dez. 1954).

* Remédios processuais da administração e contra administração. (a. 8, n. 8, p. 100-113, 1960).

" Tratamento jurídico da retrocessão. (a. 12, n. 12, p. 191, 202, 1969).

\section{DIREITO ADQUIRIDO}

* O direito adquirido diante do futuro código civil. Sujejtos de direito. Pessoas físicas. (a. 19, n. 19, p. 63-86, 1978/79/80).

\section{DIREITO AÉREO}

" Direito astronáutico: diretrizes e normas. (a. 6/7, n. 6/7, p. 101-125, 1958/59).

* Impunidade das infrações a regras de aviação cometidas em alto mar. (a. 10, n. 10, p. 61-74, 1964/67).

\section{DIREITO BANCÁRIO}

" Reforma do sistema bancário. (a. 5, n. 5, p. 121-152, dez. 1957).

\section{DIREITO CIVIL}

"A ficção no direito. (a. 11, n. 11, p. 145-160, 1968).

- A função renovadora do direito. (a. 12, n. 12, p. 39-48, 1969). 
* Os princípios Gerais do Direito Civil. (a. 22, n. 22, p. 272-285, 1985).

\section{DIREITO COMPARADO}

* O direito comparado. (a. 15, n. 15, p. 261-274, 1972).

" Direito comparado e geografía jurídica. (a. 3, n. 3, p. 348-371, dez. 1955).

* Le droit comparé et l'unification du droit privé des pays latins. (a. 5, n. 5, p. 193-200, dez. 1957).

* Garantias juridicionais dos administrados em direito comparado. (a. 18, n. 18, p. 1976/77).

* Instituto de direito comparado ra Universidade Federal do Paraná. (a. 6/7, n. 6/7, p. 85-100. 1958/59).

\section{DIREITO CONSTITUCIONAL}

* O excesso de adaptação das cartas estaduais à constituição de 1967. (a. 12, n. 12, p. 151-172, 1969).

* Interpretação das normas constitucionais. (a. 22, n. 22, p. 158-165, 1985).

* Métodos e processos de interpretação constitucional. (a. 22, n. 22, p. 146-157, 1985).

\section{DIREITO DE FAMÍLIA}

* Poder da binuba sobre os filhos do leito anterior. (a. 4, n. 4, p. 131-142, dez. 1956).

* O repúdio das mulheres pelo marido no direito muçulmano, visto pelo Supremo Tribunal Federal. (a. 20, n. 20, p. 133-160, 1981/82).

\section{DIREITO DO CONSUMIDOR}

" El derecho procesal y la proteccion del consumidor. (a. 21 , n. 21 , p. 121-128, 1983/84).

\section{DIREITO DO TRABALHO}

* $O$ destino do direito do trabalho. (a. 5, n. 5, p. 153-165, dez. 1957).

* A eqüidade e o direito do trabalho. (a. 19, n. 19, p. 17-39, 1978/79/80).

" Jus novum. (a. 6/7, n. 6/7, p. 126-143, 1958/59).

\section{DIREITO FISCAL}

* Política fiscal em países subdesenvolvidos. (a. 3, n. 3, p. 21-99, dez. 1955). 


\section{DIREITO INTERNACIONAL}

* Lei reguladora do estatuto pessoal. (a. 2, n. 2, p. 19-43, dez. 1954).

* Pessoas interriacionais. (a. 6/7, n. 6/7, p. 238-267, 1958/59).

* O problema da soberania e o direito das gentes. (a. 1, n. 1, p. 170-177, dez. 1953).

* Restrições e concessões aos direitos dos estrangeiros. (a. 4, n. 4, p. 35-62, dez. 1957).

* Sentenças estrangeiras do divórcio. (a. 5, n. 5, p. 223243, dez. 1957).

* Sentenças estrangeiras meramente declaratórias do estado das pessoas. (a. 9, n. 9, p. 29-32, 1961/63).

" Sobre as doutririas do reconhecimento. (a. 4, n. 4, p. 9-19, dez. 1956).

\section{DIREITO INTERNACIONAL PRIVADO}

* A realidade multinacional e as implicações da nacionalidade no direito internacional privado. (a. 25, n. 25, p. $1-58,1989)$.

* Sistemas determinadores da nacionalidade da pessoa jurídica e o direito internacional privado brasileiro. (a. 12, n. 12, p. 241-256, 1969).

\section{DIREITO NATURAL}

" Coriceito clássico e post-clássico do jus naturale e do jus gentium. (a. 1, n. 1, p. 26-47, dez. 1953).

" Direito natural-direito cultural. (a. 4, n. 4, p. 126-130. dez. 1956).

* O direito natural em Roma. (a. 24, n. 24, p. 43-56, 1987/88).

* Em que sentido o direito natural é natural. (a. 2, n. 2, p. 158-173, dez. 1954).

\section{DIREITO PENAL}

* Anibal Bruno e a reforma penal. (a. 18, n. 18, p. 23-42, 1976/77).

* O consentimerito do ofendido no direito penal. (a. 12, n. 12, p. 257-270, 1969).

* Estado de necesșidade e a exigibilidade de outra conduta. (a. 15 , n. 15 , p. 185-207, 1972). 
* O hipnotismo e a legislação penal brasileira. (a. 5, n. 5, p. 9-26, dez. 1957).

* Interpretação da lei penal. (a. 17, n. 17, p. 135-144, 1974/75).

* A periculosidade criminal. (a. 4, n. 4, p. 63-82, dez. 1956).

" Tipo formal. (a. 24, n. 24, p. 1-16, 1987/88).

\section{DIREITO PRIVADO}

* A possibilidade da unificação do direito privado hispanoluso-americano. (a. 2, n. 2, p. 9-18, dez. 1954).

\section{DIREITO ROMANO}

* Da iniciativa das provas e dos poderes do juiz de direito romano e na atualidade. (a. 20, n. 20, p. 19-38, 1981/82).

* O direito romano em sua evolução histórica. O passado e o presente. (a. 20, n. 20, p. 161-170, 1981/82).

* Do conceito romano de imperium e seus desvios jurídico-políticos. (a. 23, n. 23, p. 19-36, 1986).

* Do tribunato da plebe e do conceito romano de justiça: breves considerações. (a. 23, n. 23, p. 9-18, 1986).

\section{DIREITO TRIBUTÁRIO}

" Dos crimes contra a ordem tributária. (a. 22, n. 22, p. 202-209, 1985).

" Estudos de direito tributário. (a. 16, n. 16, p. 63-140, 1973).

\section{DIREITOS CIVIS}

* Tutela dos direitos no código civil português. (a. 12, n. 12, p. 115-136, 1969).

\section{DIREITOS HUMANOS}

* Os antecedentes da Declaração dos Direitos de 1789 e sua evolução. (a. 24, n. 24, p. 135-152, 1987/88).

* Convenção européia de direitos humanos e convenção americana de direitos humarios em comparação. (a. 23 , n. 23 , p. $51-72,1986)$.

* Liberdades fundamentais da pessoa humana em face do Estado. (a. 3, n. 3, p. 172-252, dez. 1955).

\section{DIVÓRCIO}

* Da necessidade do divórcio. (a. 4, n. 4, p. 110-125, dez. 1956). 
* Sentenças estrangeiras do divórcio. (a. 5, n. 5, p. 223-243, dez. 1957).

\section{DOENÇAS PROFISSIONAIS}

* Reumatismo, doença do trabalho. (a. 5, n. 5, p. 109-120, dez. 1957).

DOLO

* Considerações sobre o dolo. (a. 2, n. 2, p. 303-313, dez. 1954).

* Espécies de dolo e outros elemeritos subjetivos do tipo. (a. 14, n. 14, p. 107-120, 1971).

DOMíNIO (Direito civil).

* Da etimologia e definição do domínio. (a. 8, n. 8, p. 147-152, 1960).

\section{ECONOMIA}

* Industrialismo em escala econômica. (a. 8, n. 8, p. 128-134, 1960).

* Interpretação econômica da instabilidade política nacional. (a. 2, n. 2, p. 271-286, dez. 1954).

* Síntese analítica da conjuntura econômica do Paraná e do Brasil em 1958. (a. 6/7, n. 6/7, p. 63-70. 1958/59).

\section{ECONOMIA, ENSINO DE}

* Ensino profissional de economia. (a. 3, n. 3, p. 297-303, dez. 1955).

\section{EDUCAÇÃO}

* Ainda as diretrizes e bases da educação nacional. (a. 8, n. 8, p. 55-80, 1960).

* Educação e tecnologia. (a. 5, n. 5, p. 201-216, dez. 1957).

* Enquanto se espera pelas diretrizes e bases. (a. 1, n. 1, p. 73-90, dez. 1953).

* Problemas modernos de educação. (a. 3, n. 3, p. 313-321, dez. 1955).

* Unidade educacional. (a. 3,n . 3, p. 9-20, dez. 1955). EMBARGOS DE DESLARAÇÃO

* Embargos de declaração. (a. 25, n. 25, p. 59-80, 1989). 


\section{EMBARGOS DE TERCEIROS}

* Embargos de terceiro à penhora: a questão da posse do promitente comprador. (a. 24, n. 24, p. 17-30, 1987/88).

\section{EMBRIAGUEZ}

* A embriaguez da vítima na etiologia do delito. (a. 5, n. 5, p. 54-58, dez. 1957).

* Embriaguez no direito penal. (a. 4, n. 4, p. 257-284, dez. 1956).

\section{EMPRESAS}

* Algo sobre a empresa. (a. 11, n. 11, p. 67-80, 1968).

* La nueva empresa. (a. 11, n. 11, p. 19-50, 1968).

\section{EMPRESAS PÚBLICAS}

* Autarquias e empresas públicas. (a. 15, n. 15, p. 20-42, 1972).

ERRO (Direito Penal)

* O erro em matéria penal. (a. 5, n. 5, p. 35-53, dez. 1957).

ESTADO DE DIREITO

* O estado de direito e o direito de ação (a extensão do seu exercício. (a. 19, n. 19, p. 243-262, 1978/79/80).

* O estado de direito e os direitos da personalidade. (a. 19 , n. 19, p. 223-242, 1978/79/80).

* Estado de direito e segurança nacional. (a. 19, n. 19, p. 161-184, 1978/79/80).

* A função social da empresa no estado de direito. (a. 19, n. 19, p. $263-280,1978 / 79 / 80$ ).

* A motivação da sentença como garantia inerente ao estado de direito. (a. 19, n. 19, p. 281-294, 1978/79/80).

ÉTICA PROFISSIONAL

* Os mandamentos. (a. 20, n. 20, p. 11-18, 1981/82).

EXECUÇÃO

* Processo de execução - alguns temas polêmicos (a. 19$, n. 19 , p. $127-146,1978 / 79 / 80)$.

EXECUÇÃO PENAL

* Problemas atuais de execução penal. (a. 20, n. 20, p. 51-70, 1981/82). 


\section{FALÊNCIA}

* Títulos hábeis para o pedido de falência. (a. 3, n. 3, p. 322-336, dez. 1955).

\section{FILHO}

* Poder da binuba sobre os filhos do leito anterior. (a. 4, n. 4, p. 131-142, dez. 1956).

\section{FILOSOFIA DO DIREITO}

* Comentário à ponência do Prof. Lourival Vilanova, intitulada: "o substrato modalmente indiferente. (a. 24, n. 24 , p. 39-42, $1987 / 88$ ).

* A dialética da práxis na teoria egológica do direito. (a. 22, n. 22, p. 236-249, 1985).

* Direito e dialética. (a. 17, n. 17, p. 145-158, 1974/75).

* O estado singular e o direito plural. (a. 25, n. 25, p. 139-164, 1989).

* Filosofia do direito como problema filosófico. (a. 17, n. 17, p. 9-20, 1974/75).

* Sobre direito e ideologia. (a. 22, n. 22, p. 262-271, 1985).

FINANÇAS PÚBLICAS

* A contribuição das finanças públicas para estabilidade financeira interna e externa. (a. 4, n. 4, p. 170-233, dez. 1956).

* A contribuição das finanças públicas para a estabilidade financeira interna e para o equilíbrio da balança de pagamentos. (a. 2. n. 2, p. 374-393, dez. 1954).

* Relações financeiras da União com as outras órbitas de governo. (a. 1, n. 1, p. 5-25, dez. 1953).

\section{FUNDAÇÕES}

* A fundação como forma de empresa. (a. 15, n. 15, p. 43-73, 1972).

\section{FURTO}

* Alguns aspectos do furto neurótico. (a. 1, n. 1, p. 91-97, dez. 1953).

HART, HERBERT LIONEL ADOLPHUS, 1907

* O conceito de direito em Hart. (a. 24, n. 24, p. 105-134, 1987/88). 


\section{HOMICÍDIO}

* Um novo caso de qualificativa penal em homicídio. (a. 2, n. 2, p. 69-75. dez. 1954).

\section{IMPEACHMENT}

"O "impeachment" dos executivos nomeados no direito constitucional brasileiro. (a. 17, n. 17, p. 39-52, 1974/75).

* Impeachment e impedimento do titular do poder executivo. (a. 16, n. 16, p. 141-150, 1973).

\section{IMPUTABILIDADE PENAL}

* Apontamentos sobre os estados de perturbação geral da consciência. A emoção e a paixão. (a. 20, n. 20, p. 105-132, 1981/82).

* A imputabilidade e o princípio psiquiátrico-psicológicojurídico. (a. 10, n. 10, p. 11-22, 1964/67).

\section{IMUNIDADES}

"Imunidades parlamentares. (a. 22, n. 22, p. 166-179, 1985).

ÍNDIO

* A legislação fóssil do Brasil e a menoridade social dos selvagens. (a. 4, n. 4, p. 20-34, dez. 1956).

INVESTIMENTOS - DICIONÁRIO

* Dicionário do investidor. (a. 16, n. 16, p. 9-62, 1973).

JORNADA DE TRABALHO

* Origens da limitação legal da jornada de trabalho. (a. 22, n. 22, p. 250-261, 1985).

JUIZ

* Formação e aperfeioçamento de juízes. (a. 8, n. 8, p. 114-123, 1960).

JUSTIÇA

* Alguns comentários sobre a administração da justiça na União Soviética. (a. 13, n. 13, p. 11-32, 1970).

LEIS

A generalidade da lei. (a. 8, n. 8, p. 22-43, 1960).

* As migrações do direito. (a. 4, n. 4, p. 307-323, dez. 1956).

* As migrações do direito romano. (a. 5, n. 5, p. 244-282, 1957). 


\section{LOBBY}

* Considerações sobre grupos de pressão. (a. 6/7, n. 6/7, p. $165-178,1958 / 59)$.

\section{MANDADO DE SEGURANÇA}

* Do mandado de segurança contra o ato jurisdicional no direito brasileiro. (a. 9, n. 9, p. 11-18, 1961/63).

* O mandado de segurança como instrumento de liberdade civil e de liberdade política. (a. 19, n. 19, p. 5-16, 1978/ $79 / 80$ ).

* As origens luso-brasileiras do mandado de segurança. (a. 21,n. 21, p. 1-12, 1983/84).

MANDADO DE SEGURANÇA (URUGUAI)

* "El amparo", el mandado de segurança y el sistema de garantias jurisdiccionales del derecho Uruguayo. (a. 8, n. 8, p. 153-171, 1960).

\section{MEDICINA LEGAL}

* Alguns aspectos da problemática médico-social do complexo de inferioridade. (a. 8, n. 8, p. 81-99, 1960).

* Aplicação judiciária da narco-análise. (a. 5, n. 5, p. 217-222, dez. 1957).

* Dois anos de sexologia forense no Departamento Médico Legal no Paraná. (a. 5, n. 5, p. 27-34, dez. 1957).

" Papel da má literatura dos "comics" norte-americanos sobre o psiquismo das crianças e dos adolescentes. (a. 9, n. 9, p. 73-84, 1961/63).

* Televisão - problema médico-social de relevo. (a. 11, n. 11 , p. 115-132, 1968).

\section{MINISTÉRIO PÚBLICO}

* Encargos do ministério público no ramo civil. (a. 2, n. 2, p. 291-302, dez. 1954).

MULHER CASADA

* Do aval dado por mulher casada sem o consentimento do marido. (a. 25, n. 25, p. 183-188, 1989).

MUNICÍPIOS

* O Município na evolução constitucional do Brasil. (a. 18 , n. 18 , p. $43-50,1976 / 77)$. 
NABUCO, JOAQUIM (HOMENAGEM)

* Joaquim Nabuco. (a. 2, n. 2, p. 76-92, dez. 1954).

NACIONALIDADE

* A realidade multinacional e as implicações da nacionalidade no direito internacional privado. (a. 25, n. 25, p. $1-58,1989)$.

NEGÓCIO JURÍDICO

* Negócio fiduciário, negócio indireto e negócio simulado - uma tentativa de distinção. (a. 15, n. 15, p. 248-260, 1972).

NORMA JURÍDICA

* A teoria da norma jurídica de N. Bobbio e o direito penal brasileiro. (a. 22, n. 22, p. 220-223, 1985).

\section{NOTIFICAÇÃO}

* Citação pelo correio. a(. 18, n. 18, p. 83-90, 1976/77).

* La notificación automática en la Província de Santa Fé. (a. 21, n. 21, p. 129-140, 1983/84).

\section{OBRIGAÇÕES}

* O direito das obrigações no código civil português. (a. 12, n. 12, p. 93-100, 1969).

* O probiema da causa nas obrigações contratuais. (a. 6/7, n. $6 / 7$, p. $71-84,1958 / 59)$.

ONU

"Funcionamento da ONU. (a. 13, n. 13, p. 33-46, 1970).

" As tropas da ONU e seu estatuto jurídico. (a. 1, n. 1, p. 98-120, dez. 1953).

PENA (DIREITO)

* Alguns aspectos da individualização da pena. (a. 6/7, n. 6/7, p. 228-237, 1958/59).

* Apontamentos sobre a individualização da pena. (a. 11, n. 11, p. 173-186, 1968).

" Das penas principais e sua aplicação. (a. 9, n. 9, p. 63-72, 1961/63).

" Pena privada de liberdade. (a. 13, n. 13, p. 167-206, 1970). 
- Teorias atuais da pena e o projeto de reforma penal brasileiro. (a. 22, n. 22, p. 186-201, 1985).

* Uma visão sistemático-dogmática da pena. (a. 19, n. 19, p. 147-160, 1978/79/80).

PERDÃO JUDICIAL

"A "clementia principis" de nossos dias, no direito nacional. (a. 6/7, n. 6/7, p. 203-210, 1958/59).

PERSONALIDADE (DIREITO)

* Considerações sobre os direitos da personalidade na antiga Roma. (a. 24, n. 24, p. 57-74, 1987/88).

* Personalidade jurídica da sociedade irregular. (a. 10, n. 10, p. 139-162, 1964/67).

PESSOA JURÍDICA

* Sistemas determinadores da nacionalidade da pessoa jurídica e o direito internacional privado brasileiro. (a. 12, n. 12, p. 241-256, 1969).

PESSOAS (DIREITO)

* La persona umana di fronte al diritto. (a. 3, n. 3, p. 253-276, dez. 1955).

PODERES, DELEGAÇÃO DE

* A delegação de poderes. (a. 2, n. 2, p. 287-290, dez. 1954).

POLÍTICA

* A ciência e a arte política. (a. 3,n . 3, p. 101-131, dez. 1955).

POSSE

* Embargos de terceiro à penhora: a questão da posse do promitente comprador. (a. 24, n. 24, p. 17-30, 1987/88). PREVIDÊNCIA SOCIAL

* Acidente de trabalho e a previdência social. (a. 11, n. 11 , p. 161-172, 1968).

PRISÃO CIVIL

" Prisão civil e "equivalente em dinheiro" no depósito acessório. (a. 25, n. 25, p. 189-206, 1989). 


\section{PROCEDIMENTO SUMÁRIO}

- Procedimento sumaríssimo: necessidade de sua reformulação. (a. 21, n. 21, p. 91-100, 1983/84).

\section{PROCESSO CIVIL}

* O código e o formalismo processual. (a. 21, n. 21, p. 13-20, 1983/84).

* Eficácia probatória do comportamento das partes. (a. 20, n. 20, p. 1-10, 1981/82).

* Julgamento conforme o estado do processo (temas polêmicos). (a. 21, n. 21, p. 75-90, 1983/84).

* Reflexões sobre direito e processo. (a. 14, n. 14, p. 45-72, 1971).

* Temas do processo civil. (a. 4, n. 4, p. 157-169, dez. 1956).

\section{PROCESSO PENAL}

* Princípios gerais do processo penal. (a. 22, n. 22, p. 210-219, 1985).

* Processo penale: legalitá, giustizia e difesa sociale. (a. 11 , n. 11, p. $7-18,1968)$.

\section{PROPRIEDADE}

* Da etimologia e definição do domínio. (a. 8, n. 8, p. 147-152, 1960).

PROTEÇÃO E DEFESA SOCIAL

* A vigilância privada: auxiliar do sistema de proteção e defesa social. (a. 24, n. 24, p. 193-204, 1987/88).

PROVA (DIREITO)

* La dinamica de la libre apreciacion de la prueba en la jurisdicion civil. (a. 6/7, n. 6/7, p. 286-318, 1958/59).

RECURSO EXTRAORDINÁRIO

* Nova conceituação do recurso extraordinário na constituição do Brasil. (a. 11, n. 11, p. 51-66, 1968).

RECURSO ORDINÁRIO

* Recurso ordinário: a amplitude do efeito devolutivo e o duplo grau de jurisdição. (a. 24, n. 24, p. 75-104, 1987/88). 
* Do direito ao nome. (a. 12, n. 12, p. 203-220, 1969).

* O registro civil da pessoa natural no direito brasileiro. (a. 5, n. 5, p. 59-67, dez. 1957).

RESPONSABILIDADE CIVIL

* A compensação e a responsabilidade extra-contratual. (a. 13 , n. 13 , p. $145-154,1970$ ).

RESPONSABILIDADE CIVIL DO ESTADO

* Considerações sobre a responsabilidade civil do Estado por fatos dos seus agentes. (a. 23, n. 23, p. 105-128, 1986).

* Responsabilidade civil do Estado e denunciação da lide. (a. 23, n. 23, p. 129-206, 1986).

* Responsabilidade civil do Estado pela intervenção no domínio econômico: material para discussão do tema. (a. 23, n. p. 269-282, 1986).

RESPONSABILIDADE DO ESTADO

* O princípio da responsabilidade do Estado - evolução e fundamentos. (a. 23, n. 23, p. 73-88, 1986).

* Responsabilidade do Estado por atividade lícita: especialidade e anormalidade do dano. (a. 23, n. 23, p. 207-226, 1986).

RESPONSABILIDADE PATRIMONIAL DO ESTADO

* Responsabilidade patrimonial do Estado. Os sujeitos que o compõem. Vítimas do dano. O usuário e o terceiro. (a. 23 , n. 23 , p. $89-104,1986$ ).

- A responsabilidade patrimonial do Estado por atos criminosos de terceiros. (a. 23, n. 23, p. 227-246, 1986).

* A tutela dos bens culturais e a responsabilidade patrimonial do Estado. (a. 23, n. 23, p. 247-268, 1986).

SANÇÃO DISCIPLINAR

* Ilícito penal e sanção disciplinar. (a. 10, n. 10. p. 51-60, 1964/67).

SEGURANÇA NACIONAL

* Estado de direito e segurança nacional. (a. 19, n. 19, p. 295-336, 1978/79/80). 
SENADOR CORREIA - BIOGRAFIA

* O Senador Correia. (a. 6/7, n. 6/7, p. 20-57, 1958/59).

SENTENÇA ESTRANGEIRA

" Homologacion de sentencia extranjera. (a. 9, n. 9, p. 19-28, 1961/63).

SEPARAÇÃO (DIREITO)

" O direito ao casamento e a sua dissolução entre os direitos fundamentais do indivíduo. (a. 19, n. 19, p. 213-222, 1978/79/80).

\section{SEPARAÇÃO DE BENS}

* Estudo sobre o casamento com separação de bens no direito comparado. (a. 8, n. 8, p. 172-188, 1960).

\section{SERVIÇO PÚBLICO}

* O conceito de serviço público e o direito administrativo. (a. 2, n. 2, p. 148-157, dez. 1954).

* Modas e práticas legais na execução dos serviços públicos. (a. 17, n. 17, p. 21-38, 1974/75).

SOCIEDADES COMERCIAIS

* A cisão de sociedades. (a. 18, n. 18, p. 91-94, 1976/77).

* Das sociedades coligadas e controladas. (a. 6/7, n. 6/7, p. 144-164, 1958/59).

* A instituição do mandato nas sociedades limitadas. (a. 1, n. 1, p. 179-186, dez. 1953).

SOCIEDADES POR AÇÕES

* Ações de companhias e sua negociação obrigatória em pregão público. (a. 2, n. 2, p. 262-270, dez. 1954).

* Das relações entre a companhia e seus acionistas. (a. 19 , n. 19, p. $87-100,1978 / 79 / 80$ ).

* A extinção das ações ao portador. (a. 6/7, n. 6/7, p. 9-19, 1958/59).

* Redução do capital de sociedade anônima. (a. 11, n. 11, p. 81-114, 1968).

* Reforma da lei das sociedades por ações. (a. 13, n. 13, p. 105-138, 1970).

* As sociedades anônimas de capital autorizado e de capital aberto. (a. 11, n. 11, p. 133-144, 1968). 


\section{SUICIDIO}

* Alguris aspectos psiquiátrico-legais do suicídio. (a. 6/7, n. 6/7, p. 58-62, 1958/59).

" Conceitos atuais da psicopatologia do suicídio. (a. 8, n. 8 , p. 124-127, 1960).

* Dois aspectos do tema suicídio. (a. 15, n. 15, p. 130-136, 1972).

"Velhice e suicídio. (a. 4, n. 4, p. 83-104, dez. 1956).

TABELIÃES

* O notário e o mundo de hoje. (a. 13 , n. 13, p. 47-88, 1970).

\section{TELEVISÃO}

" Televisão - problema médico-social de relevo. (a. 11, n. 11. p. 115-132, 1968).

\section{TEORIA DO DIREITO}

* O conceito de direito em Hart. (a. 24, n. 24, p. 105-134, 1987/88).

* Direito e amor. (a. 5, n. 5, p. 86-108, dez. 1957).

* A dupla interpretatividade do dever-ser. (a. 24, n. 24, p. 31-38, 1987/88).

* O estado singular e o direito plural. (a. 25, n. 25, p. 139-164, 1989).

(a. 25, n. 25 , p. $139-164,1989$ ).

* A importância da enciclopédia jurídica na formação do jurista. (a. 8, n. 8, p. 135-146, 1960).

\section{TEORIA DO ESTADO}

* A centralização no Estado Federal. (a. 22, n. 22. p. 122145, 1985).

* Fundamentos da geografia jurídica. (a. 2, n. 2, p. 174-262, dez. 1954).

* Sociedade e Estado. (a. 6/7, n. 6/7, p. 179-187, 1958/59).

* Teoria do estado composto. (a. 1, n. 1, p. 187/228, dez. 1953).

\section{TERRAS DEVOLUTAS}

* Constituições brasileiras, legislação e terras devolutas. (a. 24, n. 24, p. 153-191, 1987/88). 


\section{TERRITORIO}

* Alguns aspectos políticos e sociológicos de uma revisão territorial do Brasil. (a. 11, n. 11, p. 187-202, 1968).

- A redivisão territorial do Brasil e o poder constituinte. (a. 12, n. 12, p. 221-240, 1969).

TRATADOS INTERNACIONAIS

* A cláusula de arbitramento compulsório de litígios, nos tratados interamericanos. (a. 2, n. 2, p. 93-121, dez. 1954).

TUTELA JURISDICIONAL CAUTELAR

* Tutela sancionatória e tutela preventiva. (a. 19, n. 19, p. 117-126, 1978/79/80).

\section{UNIVERSIDADE}

* Cursos universitários - problemas do ensino médico. (a. 4, n. 4, p. 298-306, dez. 1956).

"Evolução da teoria da "universitas". (a. 2, n. 2, p. 44-68, dez. 1954).

* Fatores geográficos e cultura de grau superior. (a. 4, n. 4, p. 143-156, dez. 1956).

* La universidad latinoamericana y la eclosion pedagógica. (a. 15, n. 15, p. 15-19, 1972).

- Vagas não preenchidas em escolas superiores. (a. 4, n. 4, p. 251-256, dez. 1956).

USURA

* A destruição do homem pela ganância do poder econômico. (a. 21, n. 21, p. 21-28, 1983/84).

VILANOVA, LOURIVAL

" Comentário à ponência do Prof. Lourival Vilanova, intitulada: "o substrato modalmente indiferente". (a. 24, n. 24 , p. $39-42,1987 / 88)$.

VÍTIMA

- Contribution de la "victimologie" aux sciences criminologiques. (a. 6/7, n. 6/7, p. 268-285, 1958/59). 